\title{
Changes in The Prevalence Of Thin Bodies Biases Young Womens' Judgements about Body Size
}

\author{
Sean Devine ${ }^{1}$, Nathalie Germain ${ }^{2}$, Stefan Ehrlich ${ }^{3}$, Ben Eppinger $2,4,5,6$ \\ ${ }^{1}$ Department of Psychology, McGill University, Montreal, Canada \\ ${ }^{2}$ Department of Psychology, Concordia University, Montreal, Canada \\ ${ }^{3}$ Division of Psychological and Social Medicine and Developmental Neurosciences, Faculty of \\ Medicine, Technische Universität Dresden, Germany \\ ${ }^{4}$ Faculty of Psychology, Technische Universität Dresden, Germany \\ ${ }^{5}$ PERFORM center, Concordia University, Montreal, Canada \\ ${ }^{6}$ Department of Education and Psychology, Freie Universität Berlin, Germany
}

Corresponding author: Sean Devine [seandamiandevine@gmail.com]

Funding: This work was supported by the Natural Sciences and Engineering Research Council of Canada (N01882) and the German Research Foundation (SFB 940/2 B7) awarded to B.E. and the Social Sciences and Humanities Research Council of Canada awarded to S.D. (CGS-M 2019).

Author contributions: S.D. conceived of the initial research question, designed and programmed all experiments, analysed data, and co-authored the manuscript. N.G. assisted in the task programming and design, collected and analysed data, and provided crucial comments on the manuscript. S.E. provided theoretical insight and co-supervised the project. B.E. secured funding for the project and was the principal investigator.

Competing interests: The authors declare no conflict of interest.

Data and materials availability: All task code, raw data, and analysis scripts are available at https://github.com/seandamiandevine/PICCBI.

Preregistration. The design, hypotheses, and analyses for the current study were preregistered at https://osf.io/e28nd.

Word count: Introduction $=943 ;$ Method $=1696$; Results $=729 ;$ Discussion $\&$ Conclusion $=$ 1035; 37 references 


\begin{abstract}
Body dissatisfaction is pervasive among young women in Western countries. Among the many forces that contribute to body dissatisfaction, the overrepresentation of thin bodies in visual media has received notable attention. In this study, we propose that prevalence-induced concept change may be one of the cognitive mechanisms that explain how beauty standards shift. We conducted a pre-registered online experiment with young women $(N=419)$ and found that when the prevalence of thin bodies in the environment increased, the concept of overweight expanded to include bodies that would otherwise be judged as normal. Exploratory analyses revealed significant individual differences in sensitivity to this effect, both in terms of women's judgements about other bodies and their own. These results suggest that women's judgements about other women's bodies are biased by an overrepresentation of thinness. Policies that aim to increase size-inclusive representation in the media may be one way to curtail this influence.
\end{abstract}




\section{Statement of Relevance}

Media imagery has shaped how women judge their own and other bodies for decades. Through the promotion of a thin ideal, an overly slender standard for the female body is internalized by young women as the most suitable shape. While past work has described this phenomenon, the cognitive process(es) by which this normalization of thinness occurs are less well understood. In this study, we asked women to repeatedly judge whether or not female bodies were overweight. When presenting thin bodies more often over time, we found that women's conceptualization of thinness shifted, such that women were more likely to judge an average body as overweight when thin bodies were overrepresented. Our results provide novel insights into the cognitive mechanism underlying how visual media alter women's perception of what constitutes a normal body and why we should instead strive to portray a truthful distribution of women's bodies in our media. 
Between $13 \%$ and $32 \%$ of women in Western countries are dissatisfied with their bodies (Fallon, Harris, \& Johnson, 2014). Women with these feelings have been shown to be at an increased risk for mental and physical health problems, such as depression, cancer, and, unsurprisingly, eating disorders (Grabe, Ward, \& Hyde, 2008; Fallon et al., 2014). Among the many forces thought to contribute to body dissatisfaction, visual media has been suggested to play a major role in shifting women's concepts about ideal bodies (Grabe et al., 2008). For instance, a meta-analysis of 25 experimental studies revealed that women's body images were reliably more negative after viewing images of thin women (Groesz, Levine, \& Murnen, 2001). Theoretical work suggests that the negative effect Western media plays on body image relies heavily on its promotion of a thin-ideal (Thompson \& Stice, 2001; Tiggemann, 2002). That is, the media presents an idealized female body that becomes internalized, accepted, and endorsed by viewers through repeated exposure. Mechanistically, "repeated exposure to such images may lead women to internalize the thin ideal such that it becomes accepted by them as a reference point against which to judge themselves" (Tiggemann, 2002, p. 92).

The thin ideal refers to a standard among women portrayed in the media, who represent an unrealistically slim and tall profile, usually $15 \%$ below an average woman's weight (Hawkins, Richard, Granley, \& Stein, 2004). By the late 20th century, the ideal of female beauty had already become increasingly thinner (Sypeck, Gray, \& Ahrens, 2004) and, by the 1990s, women in popular media often met the criteria for anorexia nervosa (Wiseman et al., 1992) ${ }^{1}$. Since then, the situation has not improved. In an age of unprecedented media consumption, the thin ideal is reinforced through women's and girls' increased interaction with appearance-based

\footnotetext{
${ }^{1}$ Here we speak of women in Western societies, but there exists great cultural variation in if and how the thin ideal affects women globally. See for instance work by Hoek et al. (1998; Willemsen \& Hoek, 2006) for important discussions about cultural variability.
} 
social media platforms like Instagram and Facebook (Mingoia et al., 2017). Perhaps counterintuitively, this ideal persists even amidst the "obesity crisis" in the Western world (Blackburn \& Walker, 2005).

This persistence raises the question of how such an ideal endures in Western society, despite decades of research that has documented the negative impacts that arise from its spread through media (e.g., Swami et al., 2010; Ward, 2003; Calogero \& Thompson, 2010; Fredrickson \& Roberts, 1997; Stice \& Shaw, 1994; Evans, 2003). In other words, the cognitive processes that underlie the proliferation and internalization of the thin ideal have yet to be fully clarified (López-Guimerà et al., 2010).

In the current study, we borrow from cognitive psychology to explore one such possible mechanism: prevalence-induced concept change. Prevalence-induced concept change (or less formally, "concept creep"; Levari et al., 2018) predicts that as the numbers of exemplars of a given concept increase in the environment, the boundaries of that concept shrink such as to exclude exemplars that they would otherwise include. To assess prevalence-induced concept change, Levari and colleagues (2018) developed a task where participants had to serially judge whether individually presented dots that varied on a color spectrum between blue and purple were in fact blue or purple. When the numbers of blue and purple dots in the environment were equal across the task (50\% blue dots, $50 \%$ purple dots), peoples' judgments were stable: If they judged a dot as blue in the first trials, they judged that same dot as blue in the last trials. However, if the number of purple dots in the environment increased over the task $(50 \%$ purple dots in the first trials, but gradually shifted to $96 \%$ purple dots in the last trials), dots that were first judged as purple were later categorized as blue. Put simply, when the prevalence of purple dots in the environment increased, the boundaries for what counted as "purple" shrunk. Thus, it 
could be said the concept itself changed based on the prevalence of exemplars in the environment; hence, prevalence-induced concept change. Critically, Levari et al. (2018) showed that this change occurred not only in perceptual (color) judgements, but also arose in higher-level social and ethical judgments.

Building on the reviewed literature, we propose that the principle of prevalence-induced concept change as above may also apply in the case of body image judgements. Thus, we predict that as the prevalence of thin bodies increases in the environment, female participants will become more likely to judge women as overweight, as the concept of "thin" shrinks to now exclude bodies that were previously (with equal prevalence) considered "normal". Furthermore, we expect that young women might internalize this concept change and will become more likely to judge their own bodies as overweight. If this is the case, prevalence-induced concept change may represent a cognitive mechanism underlying the proliferation and internalization of a thin ideal in women; notably one that is driven by merely the frequency of events.

To test whether prevalence-induced concept change could explain both changes in body images judgements directed at others and the self, we conducted a preregistered online experiment using a modified version of an established task to measure prevalence-induced concept change (The Bodies Task, see Method; Levari et al., 2018; Devine et al., 2021). Specifically, we preregistered three main hypotheses (https://osf.io/e28nd):

H1. If the prevalence of thin bodies in the environment increases, women will be more likely to judge other women's bodies as overweight than if this shift did not occur.

H2. This shift in prevalence will not only affect judgments of others, but will also affect self-concept, such that women will be more likely to judge their body as overweight after being exposed to more thin bodies. 
H3. In addition to affecting women's self-concept (overweight or not), an increase in the prevalence of thin bodies in the environment will affect women's self-image, such that they will judge themselves as heavier after being exposed to this shift.

\section{Method}

\section{Participants}

An a priori power analysis revealed that we required 400 participants to detect effect sizes of

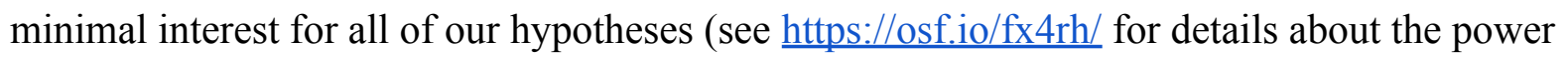
analysis). We collected data from 563 participants through Concordia University's participation pool and the online participant recruitment platform Prolific (https://www.prolific.co/).

Following our preregistered analysis plan (https://osf.io/e28nd), we excluded participants who were not aged between 18-28, who did not self-identify as female, used psychoactive substances, failed at least one catch question (see Supplement for more details) and who failed to provide a mean response time between $100 \mathrm{~ms}$ and $7000 \mathrm{~ms}$ during the Bodies Task (described below). After applying these criteria, data from 419 women were included in the final analysis (18-28 years old, $\left.M_{\text {age }}=22.60, s_{\text {age }}=2.93\right)$. The prevalence manipulation described below was between-subjects; 206 participants performed the stable condition and 213 subjects performed the increasing condition. All participants were English-speaking and free of any cognitive, visual, or motor impairments that would impede their performance (e.g., mild cognitive impairment, etc.). All participants were given a 15-character random ID and no participant was identifiable based on this ID. 


\section{Materials}

\section{Bodies Task}

The main task participants completed as part of the study was the "Bodies Task". In this experiment, participants judged whether a computer-generated body image presented on the screen was overweight or not. Stimuli for this task were taken from a publicly available and validated image bank (see Moussally et al., 2017). Sixty images of computer-generated women's bodies that ranged from emaciated to morbidly obese were used. The bodies had white skin and were wearing white underwear and a white tank top. The bodies were stopped at the neck, such that no face was visible (for examples, see Figure 1). Stimuli are available at https://osf.io/uwvs6/ and from the original authors (Moussally et al., 2017). JavaScript code for the whole experiment is freely available at https://github.com/seandamiandevine/PICCBI.

The task consisted of 800 total trials, divided into 16 blocks of 50 trials each (see Figure 1a). Each trial proceeded as follows. First, a body $(481 \mathrm{px} \times 891 \mathrm{px})$ appeared against a white background for $500 \mathrm{~ms}$. After the body disappeared, a question mark (60 px) appeared in the center of the screen after a short delay $(500 \mathrm{~ms})$, during which only a white screen was shown. The question mark remained on the screen until participants made a response. After participants made a response, another short delay occurred $(500 \mathrm{~ms})$ before the next trial began. After completing a block of (50) trials, text appeared against the white background that read "Block X. Press SPACE to continue", where X was the block number. This text remained on the screen until participants pressed continue, after which a $1000 \mathrm{~ms}$ delay occurred before the first trial of the next block.

The key manipulation in this experiment involved controlling the prevalence of thin and overweight bodies in the environment. To do so, participants were randomly assigned to one of 
two conditions (between-subjects): the stable and increasing prevalence condition. In the increasing prevalence condition, the number of thin bodies in the environment increased as the number of blocks increased in a predetermined fashion. Specifically, the proportion of thin to overweight bodies had the following order across each block in the increasing prevalence condition: $0.50,0.50,0.50,0.50,0.60,0.72, .86,0.94,0.94,0.94,0.94,0.94,0.94,0.94,0.94$, 0.94 In the stable prevalence condition, the proportion of overweight and thin bodies in the environment did not change; it was always 0.50 (see Figure 1b). Bodies were categorized as objectively thin or overweight by Moussally et al. (2017) according to WHO guidelines (WHO, 1995). Computed BMI across all bodies ranged from 13.19 (severely underweight) to 120.29 (very severely obese). On each trial, participants judged one body as being either overweight or not by pressing a key on the keyboard (A for not overweight, L for overweight). Before starting the main experiment, participants completed 10 practice trials, in which they judged 5 overweight bodies and 5 thin bodies. These practice trials were not analysed.

In addition to measuring participants' judgements of other bodies, we also assessed how changes in the prevalence of thin bodies affected participants' judgements of their own bodies. To do so, prior to completing the practice trials, participants were asked to choose a computer-generated model that they believed most resembled their own body type. This measure was based on similar assessment tools that capture participants' body image using computerized models (Stewart et al., 2009). After choosing a body, participants were then asked to judge whether they would rate this body as overweight or not. This measure was included to assess whether participants' self-concept (categorical: overweight or not) could vary independently of their self-image (continuous: where they judge their body on a spectrum). More details on our specific hypotheses for these measures will follow shortly. After completing the remainder of the 
Bodies Task (the practice trials and the 16 blocks), participants made the same continuous and categorical judgements again to determine whether the shift in prevalence affected participants' judgments about "their own" body.

\section{Questionnaires}

In addition to completing the Bodies Task, we asked participants to fill out the following questionnaires. The data from these questionnaires were not directly related to our preregistered predictions, but were collected for the purposes of exploratory analyses based on past work demonstrating links between media consumption and eating disorders (e.g., Harrison \& Cantor, 1997; Spettigue \& Henderson, 2004). Furthermore, we included three "catch questions" within these questionnaires. These questions were included for the purpose of exclusion and tested whether participants were paying attention during the experiment. Specifically, we asked participants (1) If you're paying attention please select 'Moderately' for this question. (2) If you're paying attention to this question, please select 'Rarely'. (3) If you're paying attention, please select 'Not at All' for this question. See Supplement for details about exclusion criteria for these questions.

Additionally, we asked participants to self-report the following variables: age, sex, education, height, weight, socioeconomic status, time spent consuming various types of media, and ethnicity, as well as respond to questions concerning physical and mental health. Some of these questions were also administered for the purpose of exclusion (see Supplement). Furthermore, we asked participants to complete the following questionnaires after completing the Bodies Task, described in full in Supplement: the Eating Disorder Examination 
Questionnaire-Short (EDE-QS; Gideon et al., 2016), the Body Shape Questionnaire Short Form (BSQR; Dowson \& Henderson, 2001), and the Brief Symptom Inventory-18 (BSI-18; Franke et al., 2017).

\section{Analysis}

\section{H1. Judgements of Other Bodies}

To determine whether H1 was supported by the current data, we used a logistic multilevel model that had the following form:

$$
\begin{gathered}
Y_{i j}=\beta_{0 j}+\beta_{1 j} \text { Trial }_{i j}+\beta_{2 j} \text { Size }_{i j}+\beta_{3 j}\left(\text { Trial }_{i j} \times \text { Size }_{i j}\right) \\
\beta_{0 j}=\gamma_{00}+\gamma_{01} \text { Condition }_{j}+U_{0 j} \\
\beta_{1 j}=\gamma_{10}+\gamma_{11} \text { Condition }_{j}+U_{1 j} \\
\beta_{2 j}=\gamma_{20}+\gamma_{21} \text { Condition }_{j} \\
\beta_{3 j}=\gamma_{30}+\gamma_{31} \text { Condition }_{j} .
\end{gathered}
$$

$Y_{i j}$ refers to the log odds of participant jjudging a body as overweight on trial $i: \log \left(\frac{p_{\text {overweight }}}{1-p_{\text {overweight }}}\right)$.

Trial refers to the trial number, scaled to be between 0 and 1. Size refers to the computerized model's ordinal size (in raw units: from 0 to 600, increasing in steps of 10), scaled to be between 0 and $1(0=$ thinnest $)$. Condition refers to the condition the participant was randomly assigned to (increasing or stable). $U_{0 j}$ are the random intercepts per participants, and $U_{1 j}$ are the random slopes for Trial per participant. $\gamma_{x x}$ represent fixed effects. Fixed and random effects were tested for significance using likelihood ratio tests (LRT). This model was implemented using the lme4 package (Bates et al., 2015) in R (version 3.6.3). 


\section{H2. Self-Concept}

To test whether participants' self-concept (overweight or not) was affected by increases in the prevalence of thin bodies, we conducted a logistic ordinal regression ${ }^{2}$. To avoid violations of the assumption of normality (each participant made two judgements: at the beginning and end of the task), we computed a dummy-coded difference score. Participants who judged their body as thin after the Bodies Task but who previously stated it was overweight (a "decrease" in self-concept about overweightness) were coded as -1 . Participants who did the opposite-judged their body as overweight after judging it as thin—were coded as 1. Participants who exhibited no change from before the Bodies Task to after were coded as 0 . The goal was to predict these ordinal scores $(-1$, $0,1)$ from participants' condition (increasing or stable). To do so, we fit the following model:

$$
\operatorname{logit}(p(Y \leq k))=\beta_{0 k}-\eta_{1} \text { Condition, }
$$

wherelogit $(p(Y \leq k))$ is the log odds that participants' change in self concept $(Y)$ is less than or equal to dummy code $k(-1,0,1) . \beta_{0 k}$ is the intercept for category $k$ and $\eta_{1}$ is represents the negative slope coefficient for Condition (increasing or stable): $-\beta_{1}$. The effect of Condition was tested for significance using an LRT against an intercept only model.

\footnotetext{
${ }^{2}$ We had originally preregistered to use logistic multilevel modeling (as for $\mathrm{H} 1$ ), but realized after that the small number of trial-wise observation (micro-units) made this an inappropriate analysis strategy. We nevertheless analysed our results using multilevel modeling and reached the same conclusion as the method presented in text. As such, we report the more principled approach in the Method and Results sections.
} 


\section{H3. Self-Image}

To test whether participants' self-perception varied according to whether the prevalence on thin bodies in the environment increased or not, we turned to simple linear regression ${ }^{3}$. Specifically, we computed difference scores in participants' model choice (which model they chose to represent themselves at the beginning versus the end of the task) and predicted these scores using the following model:

$$
Y_{j}=\beta_{0}+\beta_{1} \text { Condition }
$$

The significance of Condition was tested for by LRT.

To be sure that participants' judgements about models meant to represent themselves (i.e., our predictions for $\mathrm{H} 2$ and $\mathrm{H} 3$ ) were reasonably accurate reflections of their true self-image, we verified that participants chose bodies that matched with their body mass index (BMI). BMI scores were computed from participants' self-reported height and weight from the demographics questionnaire. For details about this analysis, see Supplement. In brief, we found good agreement between participants' self-report BMI and the size of the computerized models they chose to represent themselves.

\section{Results}

\section{Judgements of Other Bodies (H1)}

We found that the best fitting model to explain participants' judgements of other bodies in the Bodies Task was one that included all main effects and interactions of Size, Trial, and Condition $\left(\chi^{2}(5)=231.24, p=5.81 \times 10^{-48}\right)$. The full results from this model are summarised in Table S1. Most importantly, we found a three-way interaction between Condition, Trial, and Size

\footnotetext{
${ }^{3}$ See note above. The same issue applied in this case, with both techniques again yielding similar results. Thus, we report results from the more robust technique here.
} 
$\left(\beta=7.71, S E=0.75, p=1.39 \times 10^{-24}\right)$. As seen in Figure 2a, this result shows that when the prevalence of thin bodies in the environment increased over the course of the task, participants judged more ambiguous bodies (average bodies) as overweight than when the prevalence remained fixed. Therefore, we find strong support for $\mathrm{H} 1$ in the current sample.

\section{Self-Concept (H2)}

We did not find a significant effect of condition on participants' categorical judgements of the self $(\beta=0.06, S E=0.35, p=.8636$; see Figure $3 \mathrm{a})$. Therefore, the current data do not support H2.

\section{Self-Image (H3)}

We found a small, but statistically significant, effect of condition on participants' self-image ( $\beta=-0.01, S E=0.006, p=.0261)$. However, this effect was in the opposite direction of our initial prediction: when the prevalence of thin bodies increased, participants judged themselves as thinner than they did at the beginning of the task and compared to when the prevalence remained stable. As can be seen in Figure $3 b$ however, this effect was in part driven by a combination of baseline differences in body judgements and small effects in both conditions. As such, the significance of this effect is likely an artifact. Therefore, $\mathrm{H} 3$ is not supported by the current data.

\section{Exploratory Analyses}

In addition to our preregistered analyses, we conducted a series of exploratory analyses. In particular, we observed sizable variation in individual women's sensitivity to concept change 
during the Bodies Task (conditional ICC $=0.35$; see Table S2). In order to establish a relationship between sensitivity to concept change in judgements about others and judgements about the self, we examined whether these differences in concept change about other bodies might moderate women's sensitivity to concept change about their own. To quantify individual sensitivity to prevalence-induced concept change during the Bodies Task, we computed empirical Bayes' estimates (EB): $E B_{\text {Trial }, j}=\lambda_{j} \hat{\beta}_{\text {Trial }, j}+\left(1-\lambda_{j}\right) \gamma_{00}$, where $\lambda_{j}$ is the reliability of participants $j$ 's responses and $\widehat{\beta}_{\text {Trial, } j}$ is the estimated effect of Trial on participant $j$ 's responses. These values quantify the degree to which each woman in our sample changed their responses over the course of the experiment ${ }^{4}$. We used the same analytic techniques as discussed in the Analysis to assess whether empirical Bayes estimates predicted changes in self-concept and self-image from the beginning to the end of the experiment. We found no effect of EB on change in participants' self-image $(\beta=-0.04, S E=0.003, p=.1459$; see Figure 4a). However, we did find that individual sensitivity to concept change significantly predicted the likelihood of changing one's self concept about their size from the beginning of the task to the end $(\beta=0.49, S E=0.28, p=.0258)$. This result suggests that participants who were most susceptible to concept change when judging other bodies were also those most sensitive to concept change when judging themselves. In other words, women who experience strong concept change when judging other bodies were more likely to judge themselves as overweight after being exposed to an increase in thin bodies in the environment compared to women who were less sensitive to this change (see Figure $4 b$ ). By plotting the predicted values of this effect

\footnotetext{
${ }^{4}$ When EB are near zero, it suggests no change in response over the course of the experiment (as is the case for most participants in the stable condition). Conversely, when EB are larger than zero, it suggests that women judged more bodies as overweight at the end of the experiment, compared to the beginning (as is the case for most participants in the decreasing condition). EB smaller than zero suggest a reversal of this effect: women judged bodies as thinner at the end of the experiment compared to the beginning.
} 
(Figure 4c), we can also see that our model predicts this to occur in reverse as well-women who judge other women as thinner after an increase in the prevalence of thin women in the environment are more likely to judge themselves as thin.

Overall, these results suggest that individual differences exist in women's sensitivity to concept change in judgements about other bodies and that these differences predict how susceptible women's self-concept are to changes in the prevalence of thin bodies. However, When predicting individual sensitivity to concept change (EB) from scores on the questionnaire data we collected (see Method: Questionnaires), we found no significant relationships (see Table S2). We discuss this lack of significant associations in the next section and suggest avenues for future research.

\section{Discussion}

Following recent work (Levari et al., 2018; Devine et al., 2021), our results demonstrate that what women consider to be an "average" body shifts in accordance with the prevalence of thin bodies in the environment. Specifically, we find that when the prevalence of thin women in the environment increased, women became significantly more likely to judge other women as overweight, compared to when the prevalence remained the same; that is, 50/50. Notably, this effect was strongest for bodies of average BMI. As shown in Figure 2b, at the beginning of the experiment, few participants in either condition (increase or stable) judged a body with a BMI of $23.35^{5}$ (well-within the normal range of BMI for an adult woman) to be overweight: $11 \%$ in the increase condition and $8 \%$ in the decrease condition. By the end of the experiment however, a quarter $(25 \%)$ of participants who saw the prevalence of thin bodies in the environment increase

\footnotetext{
${ }^{5}$ This BMI value was taken by Moussally et al. (2017), who computed a BMI for all computerized models according to WHO guidelines..
} 
(those in the increase condition) judged this same body to be overweight. Conversely, in the stable condition, there was virtually no change in participants' judgements $(9 \%$ overweight judgements). This example highlights the key finding from the current study: what women deem to be a "normal" body shifts in accordance with the prevalence of bodies in the environment.

Based on these results, we propose that prevalence-induced concept change may be a general cognitive mechanism to explain how women's perception of "normal" bodies in Western society shift over time: as the prevalence of thin bodies in the media has increased over time (Sypeck et al., 2004), the reference point for normality has shifted to be ever-thinner. By general, we refer to the fact that prevalence-induced concept change has previously been shown to explain similar shifts in perceptual, social, and moral categories, making it a good candidate for a domain-general explanation of shifts in perception and judgements such as those seen in the current study (Levari et al., 2018). More precisely, the advantage of this framework in the context of women's body judgements is that media-influenced biases in judgements can be explained in purely mechanistic terms as a comparative decision-making process, wherein peoples' estimates of normality are updated by new information (see Wilson, 2018).

Importantly, this view also predicts that changes can occur in the opposite direction. That is, by increasing the prevalence of overweight women and/or reducing the overrepresentation of thin women in the social environment - i.e., balancing the two-we would expect the (already expanded) concept of "overweight" to shrink (Levari et al., 2018). Such a reversal effect has implications for representation in the media. Namely, by increasing the number of normal women's bodies in popular media, we would expect to counteract the overexpansion of the concept of overweight brought about by the thin ideal. According to the proposed mechanism then, an increased diversity of body sizes in people's social environments would yield more 
accurate judgements of normal versus overweight bodies. Indeed, in the stable condition of the current experiment, when the prevalence of thin and overweight bodies was balanced, participants were fairly accurate in their categorizations of stimuli. Anecdotally, we may be seeing just such a reversal occurring in North America: as the objective prevalence of overweight people has increased across the continent over the past four decades (Blackburn \& Walker, 2005), there has been an increased acceptance and advocacy for promotion of fat-acceptance measures in the West (Cooper, 2016). While extrapolatory, this is the exact type of normalization effect we would expect from the perspective of prevalence-induced concept change. In the E.U., countries like France and Italy, for instance, have explicitly attempted to harness such a normalizing force by passing legislation that bans overly thin fashion models from public appearances (Poggioli, 2006; Dearden, 2017). Our results lend support to similar policies and suggest that these efforts should have normalizing effects on concepts of normality about young women's bodies.

Notably, at the level of the individual, we find that women whose judgements were most biased by an increased prevalence of thin bodies were also more likely to turn this concept change inwards - i.e., they were more likely to judge themselves as overweight after being exposed to an increase in thin bodies in the environment (see Figure 4b). This result points to important individual differences in the degree to which these prevalence-induced biases in judgements affect women. In the current sample, we were not able to explain these individual differences via person-level differences in the collected measures (i.e., various subclinical eating disorder symptomatologies, see Table S2), likely due in part to an explicit attempt on our part to collect data from a homogenous sample (English-speaking, Western, young adult women from a non-clinical sample). As such, this finding opens an avenue for future research to better 
understand which individual traits moderate prevalence-induced biases in judgements at a mechanistic level: not only with regards to judgements about others, but also how this shift affects judgements about the self. One promising direction for such research would be to explore these effects in an age-comparative manner, given the well-established literature demonstrating adolescents' increased sensitivity to thin images (Harrison \& Cantor, 1997; Stice, Spangler, \& Agras, 2001). Indeed, work from our lab has found that prevalence-induced concept change is sensitive to age differences (albeit in the opposite direction: aging; Devine et al., 2021).

Another future direction might be to test these effects in a clinical sample, given that women with clinical eating disorders tend to devote more attentional resources to thin features in their environment (Pinhas et al., 2014) and display alterations in their learning of latent states (Bernardoni et al., 2018).

\section{Conclusion}

The overrepresentation of thin women in Western media creates a thin ideal, wherein thin bodies are considered "normal" and desirable. In the current study, we propose that prevalence-induced concept change is a basic cognitive mechanism by which this normalization occurs: When the prevalence of thin bodies in the environment increases, the concept of overweight expands to include bodies that would otherwise be thought of as normal. These findings have implications both for cognitive theories that explain how women judge their own and others' bodies, as well as for policy that aims to increase representation of diverse body sizes in the media. 


\section{References}

Bates, D., Mächler, M., Bolker, B., \& Walker, S. (2015). Fitting Linear Mixed-Effects Models Using lme4. Journal of Statistical Software; 67(1). https://www.jstatsoft.org/v067/i01

Bernardoni, F., Geisler, D., King, J. A., Javadi, A. H., Ritschel, F., Murr, J., Reiter, A.M.F., Rossner, V., Smolka, M.N., Kiebel, S., \& Ehrlich, S. (2018). Altered medial frontal feedback learning signals in anorexia nervosa. Biological psychiatry, 83(3), 235-243. https://doi.org/10.1016/j.biopsych.2017.07.024

Blackburn, G. L., \& Walker, W. A. (2005). Science-based solutions to obesity: What are the roles of academia, government, industry, and health care? The American Journal of Clinical Nutrition, 82(1), 207S-210S. https://doi.org/10.1093/ajen/82.1.207S

Burke, M. A., \& Carman, K. G. (2017). You can be too thin (but not too tall): Social desirability bias in self-reports of weight and height. Economics \& Human Biology, 27, 198-222. https://doi.org/10.1016/j.ehb.2017.06.002

Calogero, R. M., \& Thompson, J. K. (2010). Gender and Body Image. In J. C. Chrisler \& D. R. McCreary (Eds.), Handbook of Gender Research in Psychology: Volume 2: Gender Research in Social and Applied Psychology (pp. 153-184). Springer New York. https://doi.org/10.1007/978-1-4419-1467-5_8

Cooper, C. (2016). Fat activism: A radical social movement. HammerOn Press.

Dearden, L. (2017, May 6). France bans "unhealthily thin” models. The Independent. https://www.independent.co.uk/news/world/europe/france-bans-unhealthily-thin-model-b mi-doctors-certificate-photoshopped-images-a 7721211.html

Devine, S., Neumann, C., Levari, D., Wilson, R., \& Eppinger, B (2021). Human Ageing is Associated with More Rigid Concept Spaces. Under review. https://psyarxiv.com/uhcp7/

Dowson, J., \& Henderson, L. (2001). The validity of a short version of the Body Shape Questionnaire. Psychiatry Research, 102(3), 263-271. https://doi.org/10.1016/S0165-1781(01)00254-2

Evans, P. C. (2003). "If Only I were Thin Like Her, Maybe I Could be Happy Like Her": The Self-Implications of Associating a Thin Female Ideal with Life Success. Psychology of Women Quarterly, 27(3), 209-214. https://doi.org/10.1111/1471-6402.00100 
Fallon, E. A., Harris, B. S., \& Johnson, P. (2014). Prevalence of body dissatisfaction among a United States adult sample. Eating Behaviors, 15(1), 151-158. https://doi.org/10.1016/j.eatbeh.2013.11.007

Franke, G. H., Jaeger, S., Glaesmer, H., Barkmann, C., Petrowski, K., \& Braehler, E. (2017). Psychometric analysis of the brief symptom inventory 18 (BSI-18) in a representative German sample. BMC Medical Research Methodology, 17(1), 14. https://doi.org/10.1186/s12874-016-0283-3

Fredrickson, B. L., \& Roberts, T.-A. (1997). Objectification Theory: Toward Understanding Women's Lived Experiences and Mental Health Risks. Psychology of Women Quarterly, 21(2), 173-206. https://doi.org/10.1111/j.1471-6402.1997.tb00108.x

Germine, L., Nakayama, K., Duchaine, B. C., Chabris, C. F., Chatterjee, G., \& Wilmer, J. B. (2012). Is the Web as good as the lab? Comparable performance from Web and lab in cognitive/perceptual experiments. Psychonomic Bulletin \& Review, 19(5), 847-857. https://doi.org/10.3758/s13423-012-0296-9

Gideon, N., Hawkes, N., Mond, J., Saunders, R., Tchanturia, K., \& Serpell, L. (2016). Development and Psychometric Validation of the EDE-QS, a 12 Item Short Form of the Eating Disorder Examination Questionnaire (EDE-Q). PLOS ONE, 11(5), e0152744. https://doi.org/10.1371/journal.pone.0152744

Grabe, S., Ward, L. M., \& Hyde, J. S. (2008). The role of the media in body image concerns among women: A meta-analysis of experimental and correlational studies. Psychological Bulletin, 134(3), 460-476. https://doi.org/10.1037/0033-2909.134.3.460

Groesz, L. M., Levine, M. P., \& Murnen, S. K. (2002). The effect of experimental presentation of thin media images on body satisfaction: A meta-analytic review. International Journal of Eating Disorders, 31(1), 1-16. https://doi.org/10.1002/eat.10005

Harrison, K., \& Cantor, J. (1997). The relationship between media consumption and eating disorders. Journal of Communication, 47(1), 40-67. https://doi.org/10.1111/j.1460-2466.1997.tb02692.x

Hawkins, N., Richards, P. S., Granley, H. M., \& Stein, D. M. (2004). The Impact of Exposure to the Thin-Ideal Media Image on Women. Eating Disorders, 12(1), 35-50. https://doi.org/10.1080/10640260490267751 
Hoek, H. W., van Harten, P. N., Hermans, K. M. E., Katzman, M. A., Matroos, G. E., \& Susser, E. S. (2005). The Incidence of Anorexia Nervosa on Curaçao. The American Journal of Psychiatry, 162(4), 748-752. https://doi.org/10.1176/appi.ajp.162.4.748

Levari, D. E., Gilbert, D. T., Wilson, T. D., Sievers, B., Amodio, D. M., \& Wheatley, T. (2018). Prevalence-induced concept change in human judgment. Science, 360(6396), 1465-1467. https://doi.org/10.1126/science.aap8731

López-Guimerà, G., Levine, M. P., Sánchez-Carracedo, D., \& Fauquet, J. (2010). Influence of mass media on body image and eating disordered attitudes and behaviors in females: A review of effects and processes. Media Psychology, 13(4), 387-416. https://doi.org/10.1080/15213269.2010.525737

Mingoia, J., Hutchinson, A. D., Wilson, C., \& Gleaves, D. H. (2017). The relationship between social networking site use and the internalization of a thin ideal in females: A meta-analytic review. Frontiers in Psychology, 8. https://doi.org/10.3389/fpsyg.2017.01351

Moussally, J. M., Rochat, L., Posada, A., \& Van der Linden, M. (2017). A database of body-only computer-generated pictures of women for body-image studies: Development and preliminary validation. Behavior Research Methods, 49(1), 172-183. https://doi.org/10.3758/s13428-016-0703-7

Pinhas, L., Fok, K.-H., Chen, A., Lam, E., Schachter, R., Eizenman, O., Grupp, L., \& Eizenman, M. (2014). Attentional biases to body shape images in adolescents with anorexia nervosa: An exploratory eye-tracking study. Psychiatry Research, 220(1-2), 519-526. PubMed. https://doi.org/10.1016/j.psychres.2014.08.006

Poggioli, S. (2006, December 21). Italy Works to Ban Overly Slim Models [Radio]. https://www.npr.org/templates/story/story.php?storyId=6657709

Spettigue, W., \& Henderson, K. A. (2004). Eating Disorders and the Role of the Media. The Canadian Child and Adolescent Psychiatry Review, 13(1), 16-19.

Stewart, T. M., Allen, H. R., Han, H., \& Williamson, D. A. (2009). The development of the Body Morph Assessment version 2.0 (BMA 2.0): Tests of reliability and validity. Body Image, 6(2), 67-74. https://doi.org/10.1016/j.bodyim.2009.01.006 
Stice, E., \& Shaw, H. E. (1994). Adverse effects of the media portrayed thin-ideal on women and linkages to bulimic symptomatology. Journal of Social and Clinical Psychology, 13(3), 288-308. https://doi.org/10.1521/jscp.1994.13.3.288

Stice, E., Spangler, D., \& Agras, W. S. (2001). Exposure to media-portrayed thin-ideal images adversely affects vulnerable girls: A longitudinal experiment. Journal of Social and Clinical Psychology, 20(3), 270-288. https://doi.org/10.1521/jscp.20.3.270.22309

Swami, V., Coles, R., Wyrozumska, K., Wilson, E., Salem, N., \& Furnham, A. (2010). Oppressive Beliefs at Play: Associations among Beauty Ideals and Practices and Individual Differences in Sexism, Objectification of Others, and Media Exposure. Psychology of Women Quarterly, 34(3), 365-379. https://doi.org/10.1111/j.1471-6402.2010.01582.x

Sypeck, M. F., Gray, J. J., \& Ahrens, A. H. (2004). No Longer Just a Pretty Face: Fashion Magazines' Depictions of Ideal Female Beauty from 1959 to 1999. International Journal of Eating Disorders, 36(3), 342-347. https://doi.org/10.1002/eat.20039

Thompson, J. K., \& Stice, E. (2001). Thin-Ideal Internalization: Mounting Evidence for a New Risk Factor for Body-Image Disturbance and Eating Pathology. Current Directions in Psychological Science, 10(5), 181-183. https://doi.org/10.1111/1467-8721.00144

Tiggemann, M. (2002). Media influences on body image development. In T. F. Cash \& T. Pruzinsky (Eds.), Body Image: A Handbook of Theory, Research, and Clinical Practice (pp. 91-98). Guilford Press.

Ward, L. M. (2003). Understanding the role of entertainment media in the sexual socialization of American youth: A review of empirical research. Developmental Review, 23(3), 347-388. https://doi.org/10.1016/S0273-2297(03)00013-3

World Health Organization. (1995). Physical status: The use of and interpretation of anthropometry, report of a WHO expert committee. World Health Organization. https://apps.who.int/iris/handle/10665/37003

Willemsen, E. M. C., \& Hoek, H. W. (2006). Sociocultural factors in the development of anorexia nervosa in a black woman. International Journal of Eating Disorders, 39(4), 353-355. https://doi.org/10.1002/eat.20234

Wilson, R. (2018). Sequential choice effects predict prevalence-induced concept change. PsyArXiv. https://doi.org/10.31234/osf.io/75bpy 
Wiseman, C. V., Gray, J. J., Mosimann, J. E., \& Ahrens, A. H. (1992). Cultural expectations of thinness in women: An update. International Journal of Eating Disorders, 11(1), 85-89. https://doi.org/10.1002/1098-108X(199201)11:1<85::AID-EAT2260110112>3.0.CO;2-T 
Figures

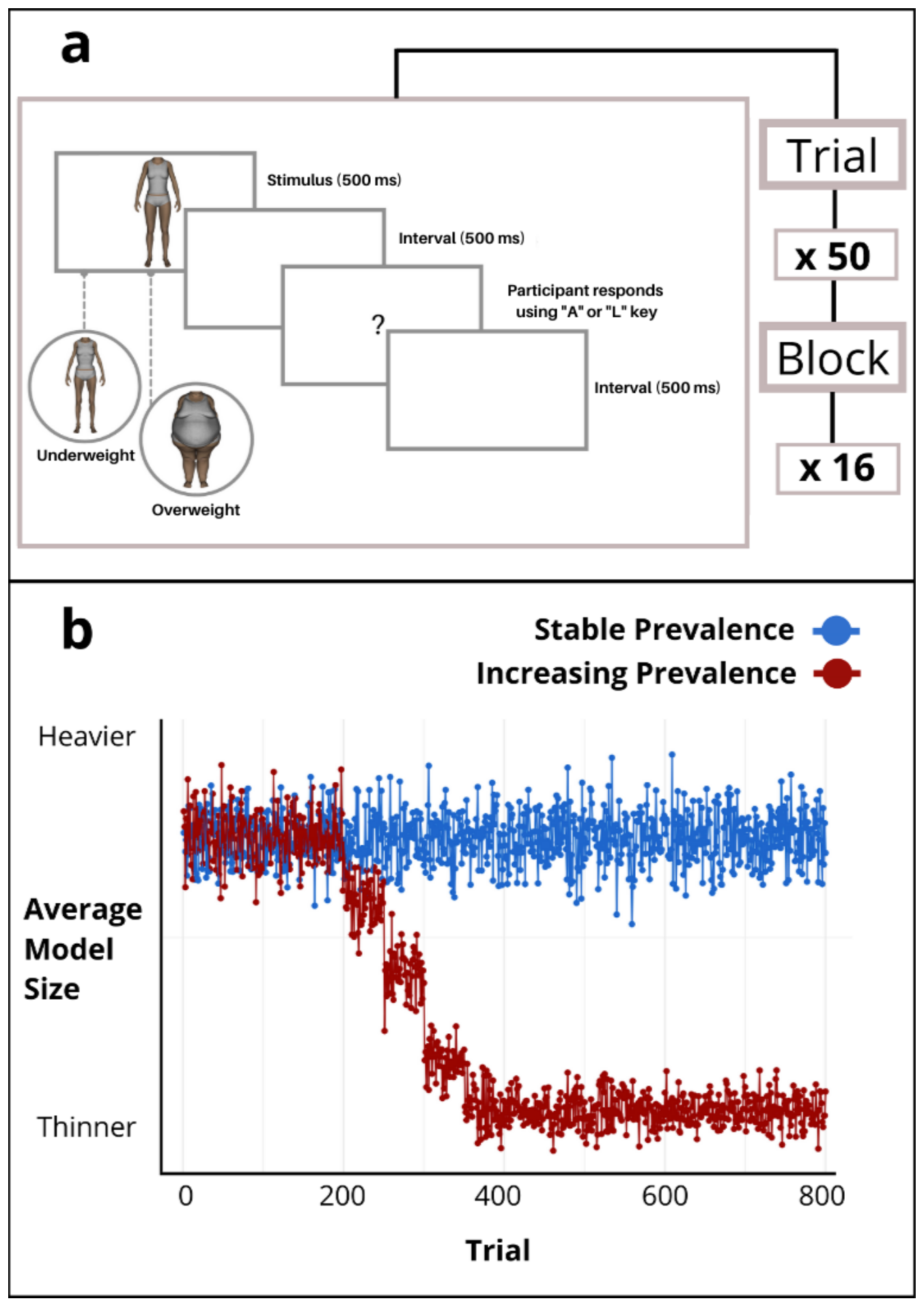

Figure 1. Bodies Task Design. (a) Schematic representation of what participants saw during the Bodies Task. (b) Average model size across trials of the Bodies task depending on condition. 


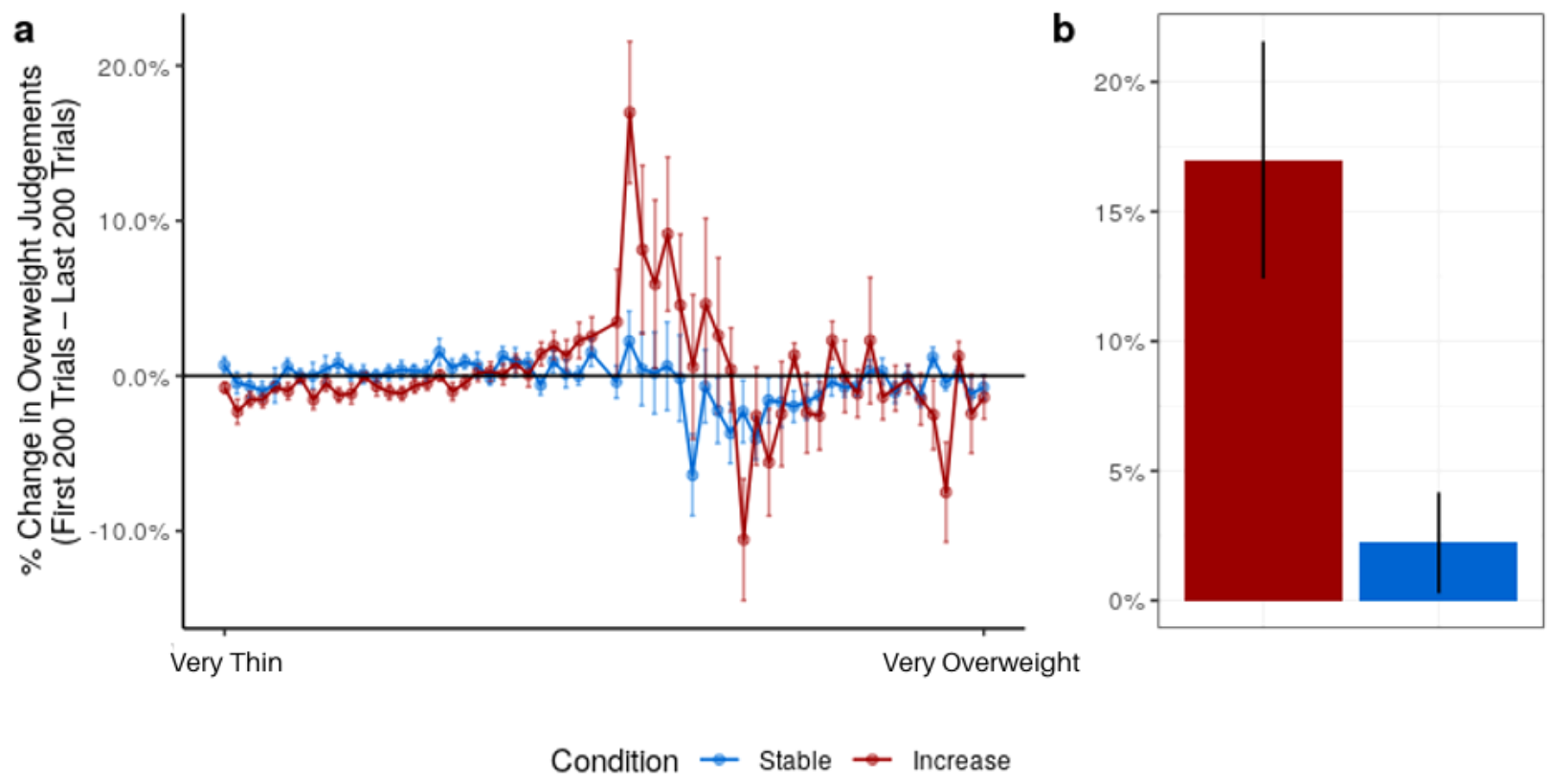

Figure 2. Model judgements during the Bodies Task. (a) The $\mathrm{x}$-axis represents the objective size of each model. The y-axis represents the degree to which participants' judgements about whether the models were overweight or not changed from the beginning of the task (first 200 trials) to the end of the task (last 200 trials) based on their condition (color). Positive numbers reflect an increase in overweight judgments and negative numbers indicate a decrease. Points represent the percent of overweight judgements made for that body. Error bars represent standard errors for each point. (b) Shows the effect in (a) for a body with a normal BMI: 23.35. Bars represent mean percent change in judgements and error bars represent standard error. 


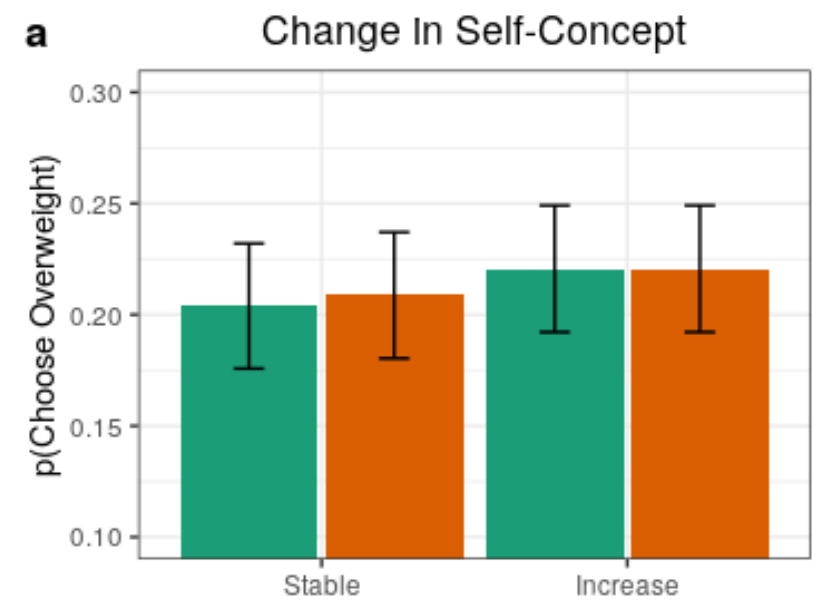

b $\quad$ Change In Self-Image

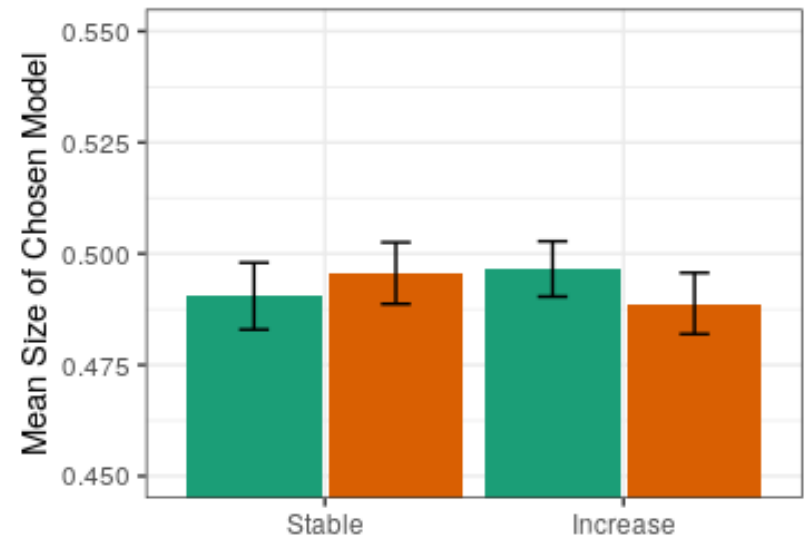

Pre-Task

Post-Task

Figure 3. (a) Categorical self-concept judgements and (b) continuous self-image judgement before and after the Bodies Task. (a) The y-axis represents the proportion of overweight judgements participants made for the model they stated best represented their own. (b) The $\mathrm{y}$-axis represents the mean size of the chosen model, scaled to be between 0 and 1 . The $\mathrm{x}$-axis in both graphs represent the condition participants' were in. Error bars represent standard error. 

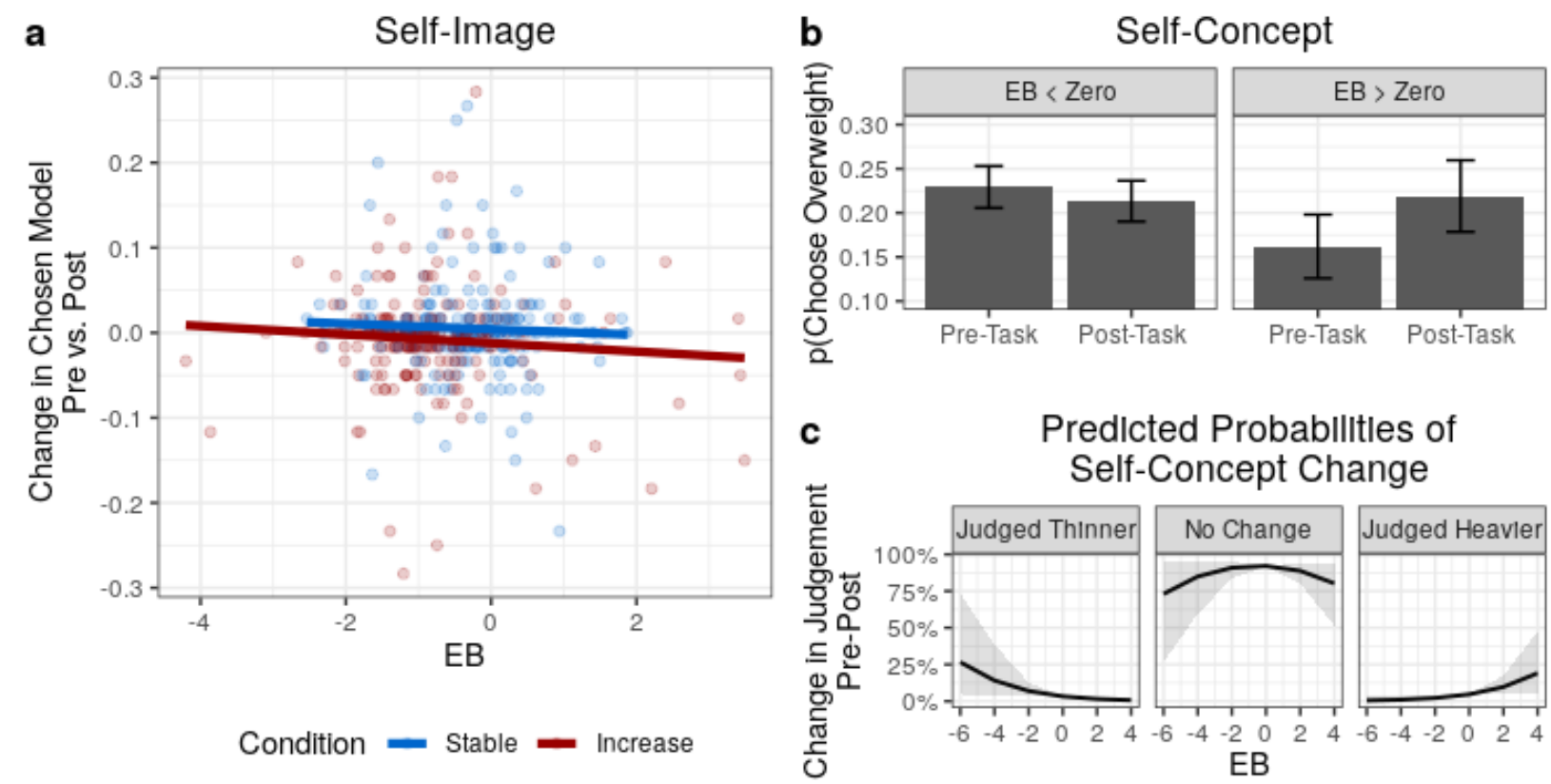

Figure 4. Relationship between sensitivity to concept change and (a) change in self-image and $(b, c)$ change in self-concept across the experiment. The $x$-axis in $(a, c)$ represent empirical Bayes' estimates of sensitivity to concept change for judgements of other bodies (see main text for more details). The y-axis in (a) represents the change in chosen model size from the beginning to the end of the task for participants in both condition (colors), (b) the proportion of overweight judgements made on these chosen models, and (c) the probability of judging the chosen model as thinner, heavier, or the the same at the end of the task compared to beginning, as predicted by an ordinal logistic regression. 


\section{Supplement}

\section{Participants Exclusion}

We collected data from a total of 563 online participants. Prior to collecting data, we preregistered exclusion criteria (https://osf.io/e28nd), because online samples are notorious for being fraught with bad data, but, when corrected for, yield similar results to in-lab studies (Germine et al., 2012). Specifically, we excluded participants for the following reasons: 1 participant was older than 30 years old, 73 participants were not women, 24 participants used some kind of psychoactive substance, 9 participants had a mean response time smaller than 100 ms or larger than $7000 \mathrm{~ms}, 17$ participants failed at least one catch question (see Method: Materials: Questionnaires), 28 participants did not finish the task all the way through, and 5 participants showed nonsensical behavior during the Bodies Task (e.g., responding with the same key for the entirety or for a significant part of the experiment). Note that some participants were excluded for multiple of these reasons and thus the sum of participants excluded for each criterion does not equal the total count of excluded participants. 


\section{Additional Questionnaires}

In addition to the questions described in the main text, we also asked participants to complete the following questionnaires after completing the Bodies Task.

Eating Disorder Examination Questionnaire-Short (EDE-QS). The EDE-QS (Gideon et al., 2016) is a 12-item questionnaire that measures eating disorder symptom severity. Participants rated how often they engage in certain disordered eating behavior on a scale of one to three, with higher scores indicating greater eating disorder symptoms. The EDE-QS has been shown to have good internal consistency and reliability (Chronbach alpha $=.91$; Gideon et al., 2016).

Body Shape Questionnaire Short Form (BSQR). The BSQR (Dowson \& Henderson, 2001) is a 14-item questionnaire that measures the strength or salience of negative body image attitudes. Questions are rated on a 6-point scale. Average scores were computed for each participant. Higher average scores indicated greater body dissatisfaction.

Brief Symptom Inventory-18 (BSI-18). The BSI-18 (Franke et al., 2017) is a questionnaire that covers three symptom dimensions of psychological distress: Somatization, Depression and Anxiety. It also provides a Global Severity Index, used to measure current or past levels of symptomatology. Respondents ranked each item on a 5-point scale, where higher scores indicated greater distress. Global Severity scores were calculated as the mean of responded items. The BSI-18 has been shown to have good internal consistency (Cronbach alpha ranging from .82 for anxiety to .93 for Global Severity Index; Franke et al., 2017). 


\section{Recruitment Procedure}

Participants found the link for the study on their Prolific homepages or through the Concordia University participant pool. After clicking on the study link, they were prompted to complete a consent form. If participants did not consent to the terms of the study, the webpage closed. If they consented to participating, they completed the demographic questionnaire. After that, they completed the Bodies Task, followed by the BSQR, the EDE-QS, and the BSI. After completing the full study, participants were thanked and compensated with course credits if they were recruited from the Concordia University participant pool or were paid a flat rate of $\$ 8.75 \mathrm{CAD}$ (£5.00 per hour) with the expectation that participants would take about one hour to complete the study if they were recruited through Prolific. The average completion time of the study was approximately 80 minutes among all participants. Among Prolific workers, the average completion time was 62 minutes (range: $26 \mathrm{~min}-130 \mathrm{~min}$ ). The current protocol was approved by the Concordia ethics committee (file number: 30013101 ). 


\section{Agreement Between Self-Reported BMI and Chosen Models}

To ensure that our measurements of self-judgement accurately reflected participants' true self-image, we assessed the relationship between participants' self-reported BMI and the size of their chosen model at the beginning of the task. Specifically, we computed participants' BMI from their reported height (in meters) and weight (in $\mathrm{kg}$ ) as follows: $B M I_{j}=\frac{\text { weight }_{j}}{\text { height }_{j}{ }^{2}}$. We then correlated their BMI to the size of the model they chose at the beginning of the experiment (prior to any prevalence change in the increasing condition). We found a significantly positive relationship between these two measures

$\left(r=0.60, t(406)=15.16, p=1.83 \times 10^{-41}, 95 \% C I=[0.54,0.66]^{6}\right)$. It is important to put this statistic in context. Chiefly, it is a well-known finding that many women regularly underestimate their weight and height during self-report (e.g., Burke \& Carman, 2017). As such, we would not expect a perfect association between these estimates. Indeed, our results are well-within the range found by other researchers who assessed the relationship between computerized body selection and BMI (Stewart et al., 2009). Overall, these results suggest that participants' chosen models reflected their self-reported BMI and thus that judgements they made about these could reasonably be assumed to reflect judgements they would make about their own bodies (i.e., the judgements predicted by $\mathrm{H} 2$ and $\mathrm{H} 3$ ).

\footnotetext{
${ }^{6}$ The reduced sample size $(\mathrm{df}=406)$ is the result of some women failing to report their height and/or weight or giving impossible responses (e.g., 25 feet tall).
} 
Table S1. Logistic Multilevel Model Results for Womens’ Model Judgements.

\begin{tabular}{|c|c|c|c|}
\hline \multirow[b]{2}{*}{ Predictors } & \multicolumn{3}{|c|}{ Response (1 = Overweight) } \\
\hline & Odds Ratios & $95 \% C I$ & $p$ \\
\hline Intercept & 0.00 & $0.00-0.00$ & $<\mathbf{0 . 0 0 1}$ \\
\hline Condition & 1.90 & $1.17-3.10$ & 0.010 \\
\hline Trial0 & 2.55 & $1.39-4.35$ & $<0.001$ \\
\hline Size0 & $2.62 \times 10^{9}$ & $1.58 \times 10^{9}-4.37 \times 10^{9}$ & $<0.001$ \\
\hline Condition $\times$ Trial0 & 0.01 & $0.00-0.01$ & $<\mathbf{0 . 0 0 1}$ \\
\hline Condition $\times$ Size 0 & 0.38 & $0.20-0.78$ & 0.008 \\
\hline Trial0 $\times$ Size 0 & 0.17 & $0.07-0.38$ & $<0.001$ \\
\hline Condition $\times$ Trial $0 \times$ Size 0 & 2222.26 & $508.01-9721.20$ & $<0.001$ \\
\hline \multicolumn{4}{|l|}{ Random Effects } \\
\hline$\tau_{00 \text { subject }}$ & 1.21 & & \\
\hline $\mathrm{ICC}$ & 0.35 & & \\
\hline $\mathrm{N}_{\text {subject }}$ & 419 & & \\
\hline Observations & 335200 & & \\
\hline Marginal $\mathrm{R}^{2}$ / Conditional $\mathrm{R}^{2}$ & $0.893 / 0.930$ & & \\
\hline
\end{tabular}

Note. The reference group for Condition is the stable condition. 
$\underline{\text { Table S2. Questionnaire Scores Predicting In-Task Behavior }}$

\begin{tabular}{|c|c|c|c|c|c|c|c|c|c|}
\hline \multirow{2}{*}{ Predictors } & \multicolumn{3}{|c|}{ EB } & \multicolumn{3}{|c|}{ Self-Image } & \multicolumn{3}{|c|}{ Self-Concept } \\
\hline & $\beta$ & $S E$ & $p$ & $\beta$ & $S E$ & $p$ & $O R$ & $S E$ & $p$ \\
\hline (Intercept) & -0.62 & 0.09 & $<0.001$ & -0.00 & 0.01 & 0.977 & & & \\
\hline EDE-QS & -0.00 & 0.01 & 0.990 & -0.00 & 0.00 & 0.807 & 1.00 & 0.05 & 0.939 \\
\hline BSQR & -0.03 & 0.07 & 0.664 & 0.00 & 0.00 & 0.709 & 1.03 & 0.27 & 0.925 \\
\hline BSI & 0.12 & 0.08 & 0.131 & -0.00 & 0.00 & 0.536 & 1.14 & 0.34 & 0.663 \\
\hline
\end{tabular}

Note. EDE-QS scores are computed as the sum of all responses, BSQR as the mean of all responses, and BSI as the Global Severity Index, which is equal to the mean of all responses. 